\title{
(-)-Epigallocatechin-3-gallate induces secretion of anorexigenic gut hormones
}

\author{
Won-Young Song, Yoshiko Aihara, Takashi Hashimoto, Kazuki Kanazawa and Masashi Mizuno* \\ Department of Agrobioscience, Graduate School of Agricultural Science, Kobe University, 1-1 Rokkodai, Nada-ku, Kobe 657-8501, Japan
}

(Received 6 April, 2015; Accepted 19 June, 2015; Published online 1 September, 2015)

\begin{abstract}
The anorexigenic gut hormones, cholecystokinin (CCK), glucagonlike peptide (GLP)-1 and peptide tyrosine-tyrosine (PYY), are released in response to food intake from the intestines. Dietary nutrients have been shown to stimulate these hormones. Some non-nutrients such as polyphenols show anorexigenic effects on humans. In the present study, we examined whether dietary polyphenols can stimulate secretion of these gut hormones. Caco-2 cells expressed mRNA of the gut hormones, CCK, PC1 (prohormone convertase 1), GCG (glucagon) and PYY. CCK, GLP-1 and PYY were secreted from Caco-2 cells after adding sugars, amino acids or fatty acids. Using Caco-2 cells, epigallocatechin-3-gallate (EGCG), chlorogenic acid and ferulic acid induced secretion of anorexigenic gut hormones. Particularly, EGCG induced secretion of all three hormones. In an ex vivo assay using murine intestines, EGCG also released CCK from the duodenum, and GLP-1 from the ileum. These results suggest that EGCG may affect appetite via gut hormones.
\end{abstract}

Key Words: epigallocatechin-3-gallate, glucagon-like peptide-1, peptide tyrosine-tyrosine, cholecystokinin

$\mathrm{F}$ ood compounds are composed of not only nutrients, but also of non-digestive compounds that affect the body. Polyphenols are one of these chemicals; they are secondary metabolites in plants and function as protective agents against stress. When consumed, dietary polyphenols help humans prevent various diseases, including obesity. ${ }^{(1)}$ One of the causes of obesity is excessive eating, which is generally regulated by the neuroendocrine system. It is possible that polyphenols affect this endocrine system and modify appetite.

Postprandial energy metabolism is regulated not only by the brain, but also by gut organs. Its regulation is mediated by nervous and endocrine systems. Peptide hormones, which are secreted from the gut epithelia in response to food compounds and mediate postprandial signals, are key players of these systems. At least 10 hormones activate the stomach and intestines, induce secretion of digestive enzymes, regulate blood glucose homeostasis, and transmit satiety signals to the brain. These hormones, which act on the brain, reach the hypothalamus, and accordingly modify appetite. ${ }^{(2)}$ Among these gut hormones, cholecystokinin (CCK), glucagon-like peptide (GLP)-1 and peptide tyrosine-tyrosine (PYY) have been shown to be the primary satiety signals. ${ }^{(3)}$ The molecular mechanisms of gut hormones' secretion are not fully understood, but recent studies using cell models have revealed that some G-protein-coupled receptors (GPCRs) and their downstream signaling molecules are involved in the exocytosis of gut hormones. ${ }^{(4-6)}$ For example, CCK is secreted through calcium sensing receptor (CaSR)-mediated signaling by aromatic amino acids, ${ }^{(5)}$ and the secretion of GLP-1 is involved in the signaling cascade from the taste receptors. ${ }^{(6)}$

The study of chemical reception of food compounds has revealed that some nutrients activate several kinds of GPCRs, including taste receptors, CaSR, and free fatty acid receptors (FFARs). Type 1 family of taste receptors, TAS1Rs, has been shown to be activated by sugars, amino acids and oligopeptides. ${ }^{(7)}$ CaSR has also been shown to respond to amino acids. ${ }^{(5)}$ FFARs respond to many kinds of free fatty acids. ${ }^{(8)}$ Recently, it has been demonstrated that some non-nutrients act on the subfamily of bitter taste receptors, TAS2Rs. ${ }^{(9)}$ Among non-nutrients, polyphenols have been reported to activate these receptors, e.g., malvidin-3 glucoside activates hTAS2R7, ${ }^{(10)}$ and epigallocatechin3 -gallate (EGCG) activates hTAS2R14 and hTAS2R39. ${ }^{(11,12)}$ On the other hand, some TAS2Rs have been shown to act as triggers for gut hormone secretion. For example, hTAS2R14 and hTAS2R38 have been shown to be involved in CCK secretion. ${ }^{(13,14)}$ Thus, it is expected that some polyphenols may also affect gut hormone release via their reception on intestinal epithelia. Actually, EGCG has been reported to have an effect on food intake reduction, resulting in prevention of obesity, ${ }^{(15)}$ which may involve an anorexigenic effect by gut hormones.

In the present study, we examined whether polyphenols induce secretion of anorexigenic gut hormones by cultured cells and animal tissues. The Caco- 2 cell line derived from a human colon cancer tissue is often used as an intestinal epithelial model for in vitro analysis of uptake of food compounds. On the other hand, Caco-2 cells partially present chromogranin A, which is widely expressed in enteroendocrine cells ${ }^{(16)}$ thus they potentially possess endocrine activity. Here, Caco-2 cells were verified to secrete anorexigenic gut hormones upon exposure to known secretagogues. Subsequently, the induction of gut hormone secretion by polyphenols was examined. Finally, the secretion of gut hormones from murine intestines was confirmed with EGCG, as an ex vivo analysis.

\section{Materials and Methods}

Chemicals. Oleic acid and resveratrol were purchased from Wako Pure Chem. Ind., Ltd. (Tokyo, Japan). Phenylalanine was from Nippon Rika (Tokyo, Japan). Quercetin was obtained from Sigma-Aldrich (St. Louis, MO). Apigenin and emodin were from Tokyo Chemical Industry (Tokyo, Japan). Cyanidin chloride and hesperidin were from Extrasynthese (Genay, France). Ferulic acid and genistein were from LKT Laboratories (St. Paul, MN). Dipeptidyl peptidase (DPP) IV inhibitor was from Calbiochem (San Diego, CA). Palmitic acid, glutamine, glucose, sucrose, chlorogenic acid hemihydrates, (-)-epigallocatechin-3-gallate, curcumin and pyruvate were obtained from Nacalai Tesque (Kyoto, Japan). All other chemicals were of the highest grade commercially available.

Cell culture and treatment. All the procedures were performed at $37^{\circ} \mathrm{C}$ unless specifically described. Caco-2 cells were

*To whom correspondence should be addressed.

E-mail: mizuno@kobe-u.ac.jp 
maintained in Dulbecco's modified Eagle's medium (SigmaAldrich) supplemented with $10 \%$ heat-inactivated fetal bovine serum in a humidified atmosphere of $95 \%$ air- $5 \% \mathrm{CO}_{2}$. Cells were used from passage 54 to 58 . For assays, cells were seeded into 24well culture plates at $2 \times 10^{5}$ cells per well and incubated for $24 \mathrm{~h}$. Subsequently, the medium was changed to a stimulant-containing assay buffer composed of phosphate buffered saline (PBS) containing $1 \mathrm{mM}$ pyruvate and $0.1 \mathrm{mg} / \mathrm{ml}$ DPP IV inhibitor. After incubation for $2 \mathrm{~h}$, assay buffers were collected and stored at $-20^{\circ} \mathrm{C}$ until used. According to the stimulants' solubility, the assay buffers were modified for each experiment. Oleic acid and palmitic acid were dissolved in dimethyl sulfoxide and diluted with assay buffer at 1:1000. Each tested polyphenols was dissolved in water containing $10 \%$ methanol and $1 \%$ trifluoroacetic acid, then diluted at 1:20 with assay buffer. The concentrations of the stimulants for the assay were as follows: glucose and sucrose, $100 \mathrm{mM}$; glutamine, $25 \mathrm{mM}$; phenylalanine, $50 \mathrm{mM}$; oleic acid and palmitic acid, $1.5 \mathrm{mM}$; apigenin, genistein, hesperidin and quercetin, $100 \mu \mathrm{M}$; cyanidin, EGCG and resveratrol, $300 \mu \mathrm{M}$; chlorogenic acid and ferulic acid, $1 \mathrm{mM}$; curcumin and emodin, $50 \mu \mathrm{M}$. The toxicity of the chemicals on Caco-2 cells was examined by measuring ATP amount in the cells and the test concentrations were determined under the toxic concentrations for each chemical.

RNA extraction from Caco- 2 cells and RT-PCR analysis. Total RNA was extracted using Sepasol (Nacalai Tesque) according to the manufacturer's instructions. Two micrograms of RNA were used for cDNA synthesis with ReverTra Ace (Toyobo, Tokyo, Japan). The primer sequences used were: 5'-CGTGACATTAAGGAGAAGCT-3' and 5'-CATACTCCTGCTTGCTGATC3' for $A C T B$ ( $\beta$-actin), 5'-CGGAAACCTGGAGAACTGCG-3' and 5'-TATCGCAGAGAACGGATGGC-3' for $C C K, \quad 5$ '-CCTTCAAGACACAGAGGAGAAATCC-3' and 5'-CCCCAACCTGTTTACATTTAGCG-3' for GCG (glucagon), 5'-GGGACAGTAGTAGCTTCCCT-3' and 5'-CATTTCCATTCTGGCTGGGA3' for $P C 1$ (prohormone convertase 1), 5'-TATGGTGTTCGTGCGCAGGC-3' and 5'-GAGGGCCCAGACCTGTGGTGA-3' for $P Y Y$. The PCR program was 30 cycles of denaturation at $98^{\circ} \mathrm{C}$ for $10 \mathrm{~s}$, annealing at $56-58^{\circ} \mathrm{C}$ for $30 \mathrm{~s}$ and extension at $68^{\circ} \mathrm{C}$ for $30 \mathrm{~s}$. The products were detected on an agarose gel by UV irradiation with ethidium bromide.

Treatment of murine intestines. This experiment was approved by the Institutional Animal Care and Use Committee (Permission number: 25-10-03) and carried out according to the Kobe University Animal Experimentation Regulations. The entire intestine of mice (ICR, male, 7 weeks, $n=6$ ) was excised and divided into duodenum, ileum and colon. Each piece of intestine was washed with Hanks' balanced salt solution (HBSS, Nacalai Tesque) and cut to a length of $0.5 \mathrm{~cm}$. These pieces were turned inside out and immersed in $0.25 \mathrm{ml}$ of HBSS containing $0.1 \mathrm{mg} / \mathrm{ml}$ DPP IV inhibitor with or without $1 \mathrm{mM} \mathrm{EGCG} \mathrm{at} 37^{\circ} \mathrm{C}$ for $45 \mathrm{~min}$. Subsequently, HBSS was collected and centrifuged at $4^{\circ} \mathrm{C}$ for $5 \mathrm{~min}$ at $1,000 \times g$ to remove debris. The supernatants were stored at $-20^{\circ} \mathrm{C}$ until measured.

ELISA. The concentration of CCK, GLP-1 and PYY was measured by ELISA (Phoenix Pharmaceuticals, Burlingame, CA), according to the manufacturer's instructions. The primary antiserum for CCK cross reacts $100 \%$ with non-sulfated CCK (26-33) (human, rat, mouse), CCK (27-33), CCK-33 (porcine), big gastrin-1 (human), caerulein, gastrin-1 (human), $42.9 \%$ with CCK-33 (human), $12.6 \%$ with CCK (30-33), and $0 \%$ with pancreatic polypeptide (human) and vasoactive intestinal polypeptide (VIP; human, porcine, rat). The primary antiserum for GLP-1 cross reacts $100 \%$ with GLP-1 (7-36) (human, rat, mouse), GLP-1 (9-36) amide, GLP-1 (1-36) amide (human), 0.4\% with GLP-1 (7-37) (human, rat, mouse), $0 \%$ with calcitonin generelated peptide (CGRP), exendin-4, glucagon (human, rat, mouse, porcine, bovine), glucose-dependent insulinotropic polypeptide,
GLP-2 (human), insulin, secretin and VIP. The primary antiserum for PYY cross reacts $100 \%$ with PYY (human), PYY (3-36) (human), 5\% with PYY (rat, mouse, porcine), PYY (3-36) (rat, mouse, porcine), $0 \%$ with amylin amide (human), glucagon (human), insulin (human), pancreatic polypeptide (human), porcine neuropeptide $\mathrm{Y}$ and substance $\mathrm{P}$. Data are presented as mean \pm SD of individual triplicate experiments.

Statistical analysis. Dunnett's test was performed to analyze the data of cultured cells. The data from the assay using murine intestines were analyzed by Student's $t$ test. Provability $(p)$ values below 0.05 were considered statistically significant.

\section{Results}

Endocrine characteristics of Caco-2 cells. The expression of genes encoding the anorexigenic gut hormones, CCK, GLP-1 and PYY, was investigated. GLP-1 is dissociated from proglucagon by PC1 during posttranslational processing. ${ }^{(17)} \mathrm{RT}-\mathrm{PCR}$ analysis demonstrated that $C C K, P C 1, G C G$ and $P Y Y$ were expressed in Caco-2 cells (Fig. 1). Together with a report that has described CCK secretion from Caco-2 cells, ${ }^{(14)}$ our results suggest that Caco-2 cells potentially secrete GLP-1 and PYY in addition to CCK.

Nutrient-dependent secretion of gut hormones from Caco- 2 cells. In humans, CCK and GLP-1 are secreted in response to food intake of dietary carbohydrates, fats and proteins, whereas PYY is induced by fats and proteins. The secretion of CCK, GLP-1 and PYY from Caco-2 cells was investigated by stimulating the cells with nutrients. CCK secretion from Caco-2 cells was induced by all the tested compounds, except glutamine (glucose, $p=0.004$; sucrose, $p=0.002$; phenylalanine, $p=0.0008$; oleic acid, $p=0.001$; palmitic acid, $p=0.01$; Fig. 2 A). GLP-1 secretion increased by all the compounds tested (glucose, $p=0.04$; sucrose, $p=0.004$; glutamine, $p=0.04$; phenylalanine, $p=0.04$; oleic acid, $p=0.002$; palmitic acid, $p=0.006$; Fig. 2B). Only two compounds, glutamine and oleic acid, stimulated PYY secretion (glutamine, $p=0.04$; oleic acid, $p=0.0001$; Fig. 2C). The results indicate that the Caco- 2 cell line is a feasible model for secretion of CCK, GLP-1 and PYY.

Non-nutrients that induce secretion of gut hormones from Caco-2 cells. There are some polyphones that reduce food intake. ${ }^{(15,18)}$ To investigate whether polyphenols can induce anorexigenic gut hormones' secretion, Caco-2 cells were directly treated with polyphenols, followed by measurement of secreted hormones into the buffer. Polyphones are largely divided into flavonoids and phenylpropanoids by the degree of polymerization of the phenol structure. Each compound from the distinct flavonoid groups was selected: quercetin as flavonols, apigenin as flavones, genistein as isoflavones, hesperidin as flavanones, EGCG as flavanols, and cyanidin as anthocyanidins. Additionally, chlorogenic acid, ferulic acid, curcumin and resveratrol were

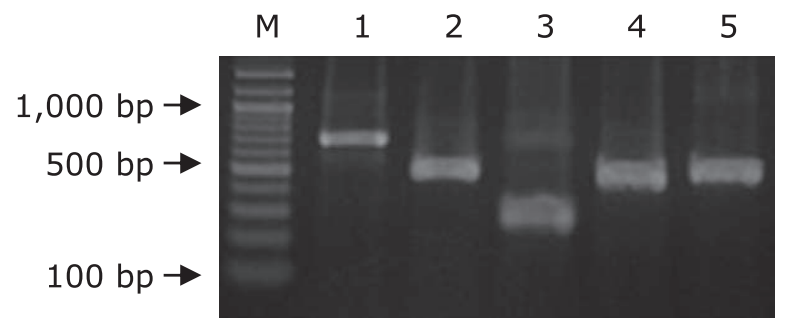

Fig. 1. Expression of enteroendocrine genes in Caco-2 cells. Transcripts of GCG (lane 1), PC1 (lane 2), PYY (lane 3) and CCK (lane 4) were detected by RT-PCR. ACTB (lane 5) was used as a positive control. Lane $M$ shows a $100 \mathrm{bp}$ DNA ladder. The expected sizes of the PCR products were 1: $758 \mathrm{bp}, 2$ : $472 \mathrm{bp}, 3: 295 \mathrm{bp}, 4: 462 \mathrm{bp}$, and 5: $470 \mathrm{bp}$. 

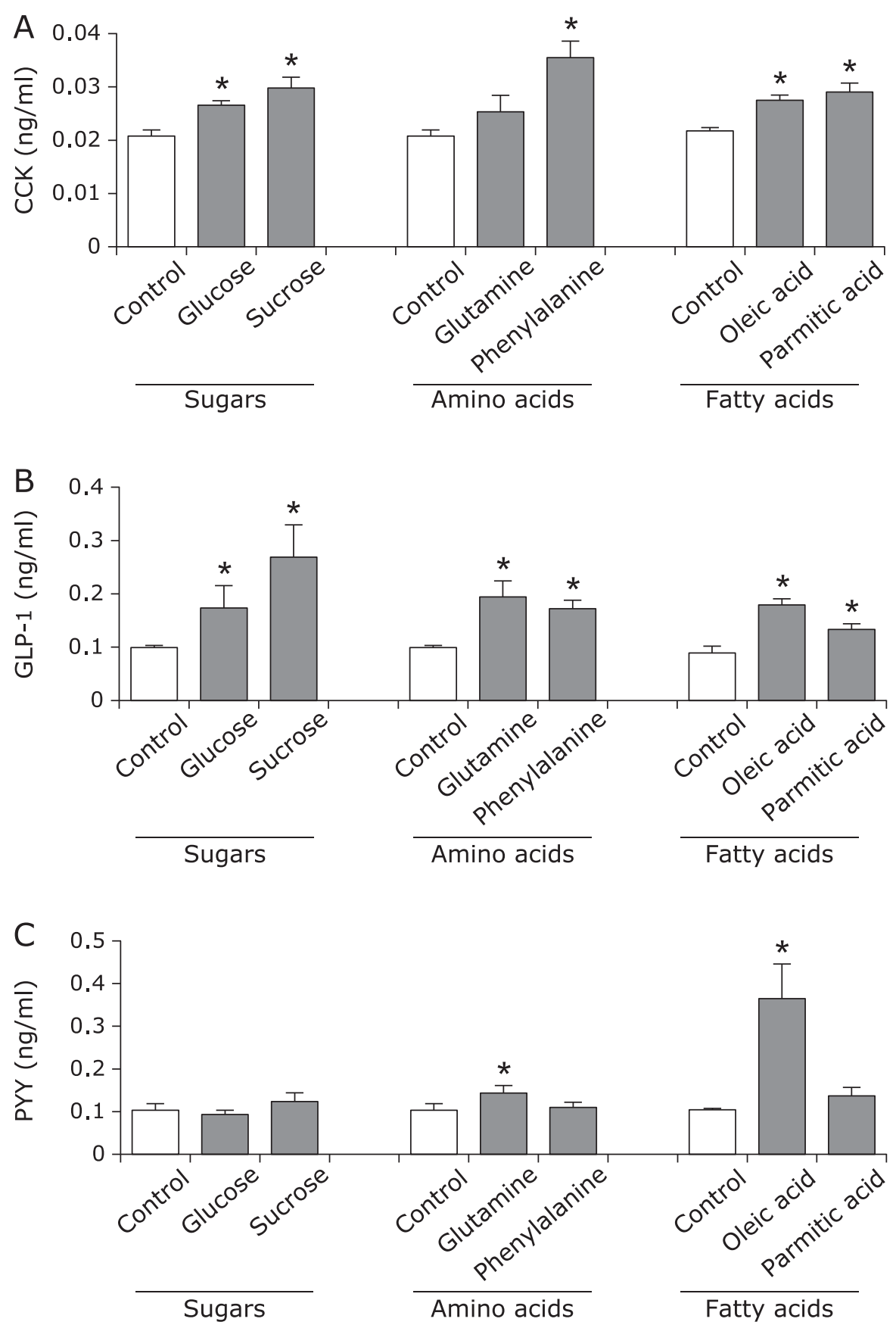

Fig. 2. Secretion of gut hormones from Caco-2 cells by stimulation of dietary nutrients. The secretion of CCK (A), GLP-1 (B) and PYY (C) from Caco-2 cells into the buffer was measured after incubation with nutrients for $2 \mathrm{~h}$. The stimulants' concentrations were: glucose, 100 mM; sucrose, $100 \mathrm{mM}$; glutamine, $25 \mathrm{mM}$; phenylalanine, $50 \mathrm{mM}$; oleic acid, $1.5 \mathrm{mM}$, and palmitic acid, $1.5 \mathrm{mM}$. A control value indicates the amount of the hormones in the assay buffer without the nutrients. * Statistical significance was determined by Dunnett's test at $p<0.05$ vs control ( $n=3$ ).

selected as phenylpropanoids, and emodin as anthraquinones. ${ }^{(1)}$ The tested concentration of polyphenols was determined according to their solubility and cytotoxicity to Caco-2 cells (data not shown). Among the polyphenols tested, EGCG significantly stimulated the secretion of CCK, GLP-1 and PYY from Caco-2 cells $(p=0.0002,0.0001$ and 0.0003 , respectively, Fig. $3 \mathrm{~A}-\mathrm{C})$. Ferulic acid induced CCK and GLP-1 secretion $(p=0.009$ and 0.002 , respectively, Fig. $3 \mathrm{~A}$ and $\mathrm{B}$ ). Chlorogenic acid increased CCK secretion ( $p=0.02$, Fig. $3 \mathrm{~A})$. The dose dependent stimulation of polyphenol on hormone secretion was analyzed using EGCG. The secretion of GLP-1 from Caco-2 cells was shown in dose dependent manner from $100 \mathrm{mM}$ to $500 \mathrm{mM}$, and shown to be induced by $300 \mathrm{mM}$ as the minimum concentration (Fig. 3D). These data support that the stimulation of EGCG is not a nonspecific signal. Taken together, it is suggested that some polyphenols induced CCK, GLP-1 and PYY secretion.

Induction of secretion of CCK, GLP-1 and PYY from murine intestines by EGCG. Gut hormones are produced in distinct endocrine cells located in different regions of the gut. CCK is secreted from I cells localized in the duodenal and jejunal mucosa. ${ }^{(19)}$ GLP-1 and PYY are released from L cells localized in the epithelia of the hind gut: ileum and colon. ${ }^{(20)}$ To show whether 

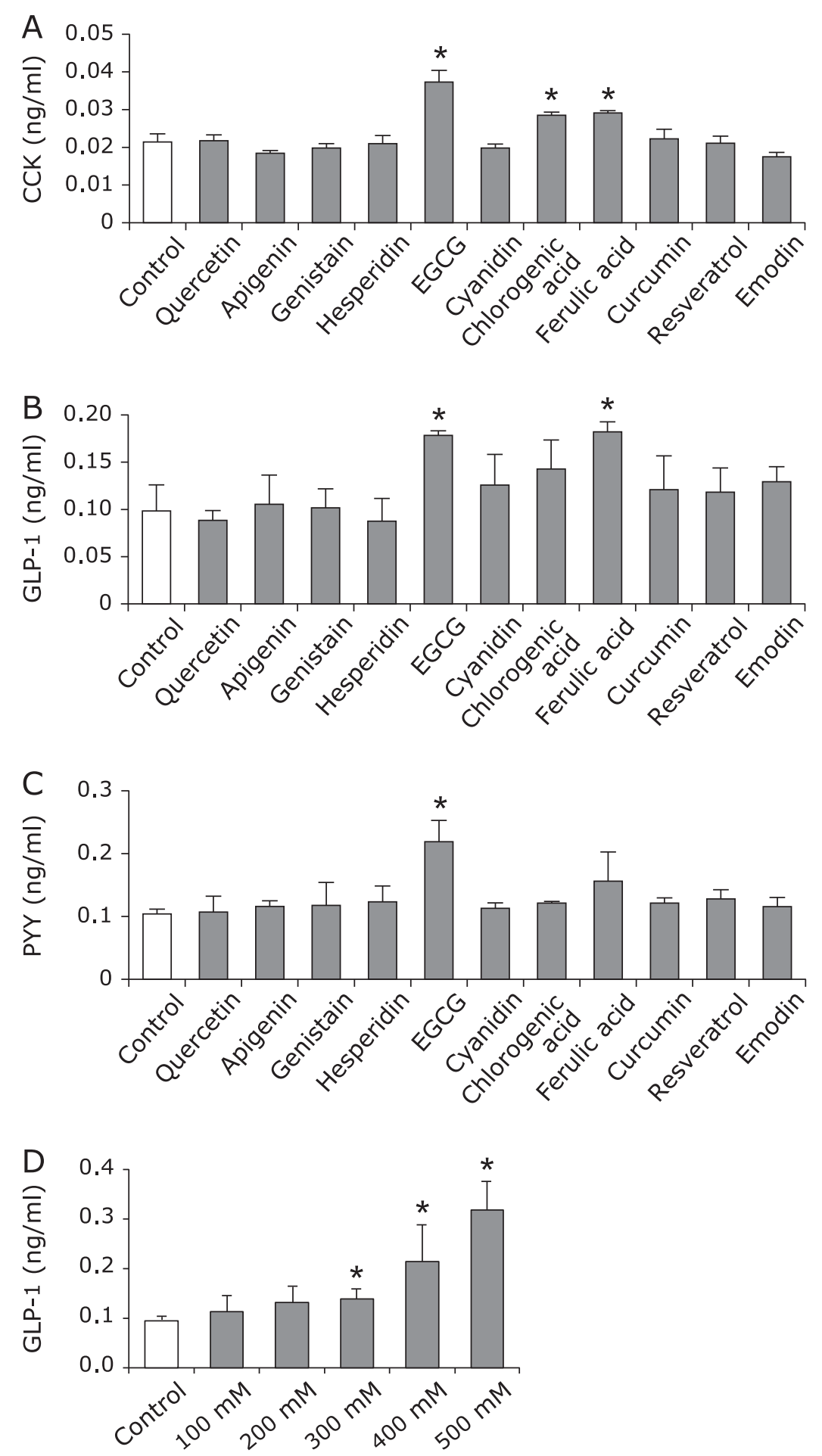

Fig. 3. Secretion of gut hormones from Caco-2 cells stimulated by polyphenols. The secretion of CCK (A), GLP-1 (B) and PYY (C) from Caco-2 cells into the buffer was measured $2 \mathrm{~h}$ after incubation with various polyphenols. The concentration of each polyphenol was: quercetin, apigenin hesperidin and genistein, $100 \mu \mathrm{M}$; EGCG, cyanidin and resveratrol, $300 \mu \mathrm{M}$; chlorogenic acid and ferulic acid, $1 \mathrm{mM}$; emodin and curcumin, $50 \mu \mathrm{M}$. (D) A dose responding secretion of GLP-1 from Caco-2 cells stimulated by EGCG. Control indicates a sample stimulated only with assay buffer. *Statistical significance was determined by Dunnett's test at $p<0.05$ vs control $(n=3)$.

the candidates for stimulants revealed by Caco-2 cells also induce gut hormones in the tissue level, an ex vivo assay was performed using the duodenum, ileum and colon from mice. EGCG was selected as the test stimulant, because it induced the secretion of all three gut hormones from Caco-2 cells (Fig. 3). Dissected murine intestines were treated for 45 min with $1 \mathrm{mM}$ EGCG, a concentration that is in the range of green tea. ${ }^{(21)}$ The results showed that CCK secretion induced by EGCG was significantly observed in the duodenum ( $p=0.006$, Fig. 4A). A slight but not significant induction of CCK secretion was observed in the ileum 

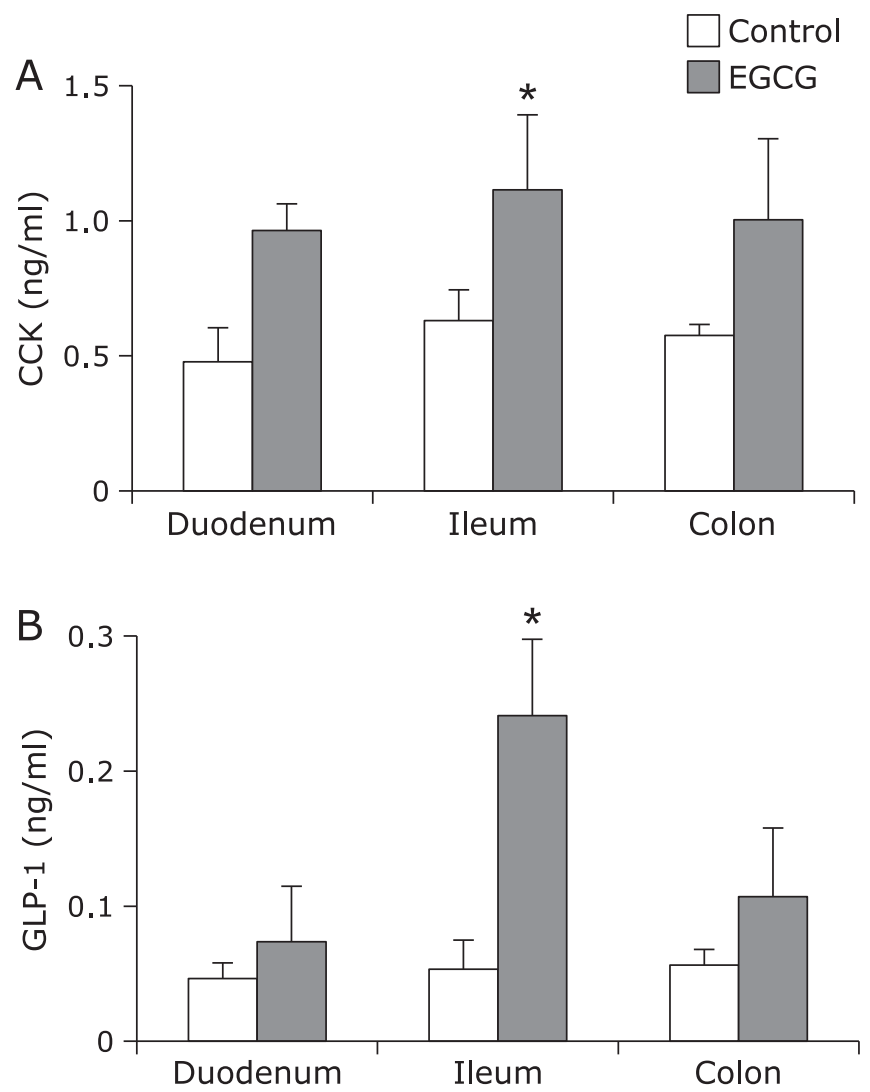

Fig. 4. Secretion of gut hormones from murine intestines in response to EGCG. The secretion of CCK (A) and GLP-1 (B) from inverted murine intestines was measured 45 min after treatment with ( $\square$ ) or without ( $\square$ ) $1 \mathrm{mM}$ EGCG. *Statistical significance was determined by Student's $t$ test at $p<0.05$ vs each control $(n=3)$.

and colon ( $p=0.05$ and 0.3 , respectively, Fig. 4A). On the other hand, it was clearly shown that GLP-1 was secreted from the ileum $(p=0.006$, Fig. 4B). These results support the notion that EGCG is able to induce anorexigenic gut hormones in animals.

\section{Discussion}

Anorexigenic gut hormones such as CCK, GLP-1 and PYY are released from the enteroendocrine cells in the gut in response to food intake. In the present study, first, we established a secretion model of anorexigenic gut hormones using Caco- 2 cells derived from a human intestinal tissue. Using this model, EGCG, chlorogenic acid and ferulic acid were shown to be potent inducers of these anorexigenic gut hormones' secretion. The dose dependent response was also confirmed by stimulation of EGCG on release of GLP-1 in Caco-2 cells. Furthermore, EGCG was shown to secrete CCK from the duodenum, and GLP-1 from the ileum in ex vivo experiments using murine intestines. The present study is the first report demonstrating that EGCG induces anorexigenic gut hormones' secretion.

The Caco-2 cell was induced to secrete CCK, GLP-1 and PYY in response to nutrients (Fig. 2). Especially, the increase in CCK secretion by glucose, phenylalanine and oleic acid, GLP-1 by sucrose and glutamine, and PYY by oleic acid was equivalent to that of direct induction in humans. ${ }^{(22-27)} \mathrm{We}$ propose that the Caco2 cell line is a good in vitro model for studying gut hormone release for several reasons. First, Caco-2 is the first human cell line, which secretes PYY in response to nutrients (Fig. 2C). Second, Caco-2 cell may compensate for CCK analysis using
HuTu- 80 cells, whose induction of CCK by nutrients has not been shown. ${ }^{(13)}$ Lastly, Caco-2 cells also compare favorably with NCIH716 cell line regarding GLP-1 secretion, because they responded to all the stimulants as NCI-H716 does. ${ }^{(6,28)}$ Hence, Caco-2 cell line is useful model for finding the stimulants which induce the secretion of anorexigenic gut hormones.

It was shown that two genes belong to human taste receptor type 2 family react to EGCG and activate the down signaling pathway. ${ }^{(11,12)}$ Recently, several molecules were shown to be involved in the downstream signaling pathway from the taste receptors in the enteroendocrine cell model. ${ }^{(29)}$ Those were gustducin as a binding G-protein, and phospholipase C- $\beta 2$ as an effector enzyme. In Caco-2 cells, the expression of $h T A S 2 R 14$, hTAS2R39, gustducin, and phospholipase $C-\beta 2$ was confirmed.

It was also observed that the gene expression of $h T A S 2 R 39$ was elevated after EGCG stimulation on Caco-2 cells. The activation of GPCR is desensitized by ligand-dependent internalization following by recycling and degradation. ${ }^{(30,31)}$ The up-regulation of receptor might indicate the recovery. This observation support that EGCG stimulate hTAS2R39 in Caco-2 cells.

There are few reports showing that non-nutrients induce gut hormones' secretion. The steroid glycoside, H.g.-12, from Hoodia gordonii has been shown to induce CCK secretion in HuTu-80 cells. ${ }^{(13)}$ This compound has also been shown to be associated with loss of body weight. ${ }^{(13)}$ Smeets et al $^{\left({ }^{(32)}\right.}$ have found that capsaicin, the pungent compound in red peppers, increased GLP-1 secretion in human plasma. Methyl syringate, a pungent ingredient in Kalopanax pictus, has been shown to significantly suppress food intake and delay gastric emptying via elevated plasma PYY levels in mice. ${ }^{(33)}$ These reports support the idea that some non-nutrients stimulate the secretion of anorexigenic gut hormones including CCK, GLP-1 and PYY, causing appetite or food intake suppression. The present study demonstrated that EGCG stimulated gut hormones' secretion from cultured Caco-2 cells (Fig. 3), and from murine duodenum and ileum (Fig. 4). It has been reported that EGCG contributes to energy expenditure, ${ }^{(21)}$ and that its consumption correlates with weight-loss led by reduction in food intake. ${ }^{(15)}$ These physiological functions of EGCG may be associated with CCK, GLP-1 and PYY secretion.

The present study also showed that ferulic acid induced the secretion of CCK and GLP-1 from Caco-2 cells (Fig. 3A and B), and that chlorogenic acid induced CCK secretion (Fig. 3A). Ferulic acid found in grains such as oats and rice has been shown to increase insulin secretion, delay intestinal glucose absorption, and inhibit gluconeogenesis. ${ }^{(34)}$ Chlorogenic acid, which is a major polyphenol in coffee, modifies the blood glucose level. ${ }^{(35)}$ Besides the anorexigenic effect on the brain, CCK and GLP-1 are known to act on glucose homeostasis. ${ }^{(36-38)}$ GLP-1 acts to stimulate glucose dependent insulin secretion, increased insulin sensitivity and inhibition of glucagon secretion. ${ }^{(36,37)} \mathrm{CCK}$ was known to induce glucagon release. ${ }^{(38)}$ The physiological effects of ferulic acid and chlorogenic acid on glucose homeostasis may be mediated by the stimulation of gut hormone secretion.

In conclusion, the Caco-2 cell line was shown to be an in vitro model for CCK, GLP-1 and PYY secretion. Some polyphenols, such as EGCG, chlorogenic acid and ferulic acid, were revealed to induce the secretion of one or several anorexigenic gut hormones. Especially, EGCG induced the secretion of these anorexigenic gut hormones in vitro and ex vivo. These results demonstrated a potential role for polyphenols in appetite regulation and control of energy balance.

\section{Acknowledgments}

This research was supported by the Japan Society for the Promotion of Science (\#24780128 to Y.A.). 


\section{Abbreviations}

CaSR

CCK

EGCG

GLP-1

GPCR

calcium sensing receptor

cholecystokinin

(-)-epigallocatechin-3-gallate

glucagon-like peptide-1

$\mathrm{G}$ protein-coupled receptor
PC1

PYY

prohormone convertase 1

peptide tyrosine-tyrosine

\section{Conflict of Interest}

No potential conflicts of interest were disclosed.

\section{References}

1 Scalbert A, Manach C, Morand C, Rémésy C, Jiménez L. Dietary polyphenols and the prevention of diseases. Crit Rev Food Sci Nutr 2005; 45: 287-306.

2 Woods SC. Dietary synergies in appetite control: distal gastrointestinal tract. Obesity (Silver Spring) 2006; 14 Suppl 4: 171S-178S.

3 Wren AM, Bloom SR. Gut hormones and appetite control. Gastroenterology 2007; 132: 2116-2130.

4 Janssen S, Depoortere I. Nutrient sensing in the gut: new roads to therapeutics? Trends Endocrinol Metab 2013; 24: 92-100.

5 Hira T, Nakajima S, Eto Y, Hara H. Calcium-sensing receptor mediates phenylalanine-induced cholecystokinin secretion in enteroendocrine STC-1 cells. FEBS J 2008; 275: 4620-4626.

6 Jang HJ, Kokrashvili Z, Theodorakis MJ, et al. Gut-expressed gustducin and taste receptors regulate secretion of glucagon-like peptide-1. Proc Natl Acad Sci U S A 2007; 104: 15069-15074.

7 Li X, Staszewski L, Xu H, Durick K, Zoller M, Adler E. Human receptors for sweet and umami taste. Proc Natl Acad Sci U S A 2002; 99: 4692-4696.

8 Hara T, Hirasawa A, Sun Q, et al. Novel selective ligands for free fatty acid receptors GPR120 and GPR40. Naunyn Schmiedebergs Arch Pharmacol 2009; 380: 247-255.

9 Meyerhof W, Batram C, Kuhn C, et al. The molecular receptive ranges of human TAS2R bitter taste receptors. Chem Senses 2010; 35: 157-170.

10 Soares S, Kohl S, Thalmann S, Mateus N, Meyerhof W, De Freitas V. Different phenolic compounds activate distinct human bitter taste receptors. J Agric Food Chem 2013; 61: 1523-1533.

11 Yamazaki T, Narukawa M, Mochizuki M, Misaka T, Watanabe T. Activation of the hTAS2R14 human bitter-taste receptor by (-)-epigallocatechin gallate and (-)-epicatechin gallate. Biosci Biotechnol Biochem 2013; 77: 1981-1983.

12 Narukawa M, Noga C, Ueno Y, Sato T, Misaka T, Watanabe T. Evaluation of the bitterness of green tea catechins by a cell-based assay with the human bitter taste receptor hTAS2R39. Biochem Biophys Res Commun 2011; 405: 620-625.

13 Le Nevé B, Foltz M, Daniel H, Gouka R. The steroid glycoside H.g.-12 from Hoodia gordonii activates the human bitter receptor TAS2R14 and induces CCK release from HuTu-80 cells. Am J Physiol Gastrointest Liver Physiol 2010; 299: G1368-G1375.

14 Jeon TI, Seo YK, Osborne TF. Gut bitter taste receptor signaling induces ABCB1 through a mechanism involving CCK. Biochem J 2011; 438: 33-37.

15 Kao YH, Hiipakka RA, Liao S. Modulation of endocrine systems and food intake by green tea epigallocatechin gallate. Endocrinology 2000; 141: 980 987.

16 Facer P, Bishop AE, Lloyd RV, Wilson BS, Hennessy RJ, Polak JM. Chromogranin: a newly recognized marker for endocrine cells of the human gastrointestinal tract. Gastroenterology 1985; 89: 1366-1373.

17 Dhanvantari S, Izzo A, Jansen E, Brubaker PL. Coregulation of glucagonlike peptide-1 synthesis with proglucagon and prohormone convertase 1 gene expression in enteroendocrine GLUTag cells. Endocrinology 2001; 142: 37 42.

18 Kim HK, Nelson-Dooley C, Della-Fera MA, et al. Genistein decreases food intake, body weight, and fat pad weight and causes adipose tissue apoptosis in ovariectomized female mice. J Nutr 2006; 136: 409-414.

19 Moran TH, Kinzig KP. Gastrointestinal satiety signals II. Cholecystokinin. Am J Physiol Gastrointest Liver Physiol 2004; 286: G183-G188.
20 Wen J, Phillips SF, Sarr MG, Kost LJ, Holst JJ. PYY and GLP-1 contribute to feedback inhibition from the canine ileum and colon. Am J Physiol 1995; 269 (6 Pt 1): G945-G952.

21 Wolfram S. Effects of green tea and EGCG on cardiovascular and metabolic health. J Am Coll Nutr 2007; 26: 373S-388S.

22 Ballinger AB, Clark ML. L-phenylalanine releases cholecystokinin (CCK) and is associated with reduced food intake in humans: evidence for a physiological role of CCK in control of eating. Metabolism 1994; 43: 735-738.

23 Hasegawa H, Shirohara H, Okabayashi Y, et al. Oral glucose ingestion stimulates cholecystokinin release in normal subjects and patients with noninsulin-dependent diabetes mellitus. Metabolism 1996; 45: 196-202.

24 Damgaard M, Graff J, Fuglsang S, Holst JJ, Rehfeld JF, Madsen JL. Effects of oleic acid and olive oil on gastric emptying, gut hormone secretion and appetite in lean and overweight or obese males. ESPEN J 2013; 8: e8-e14.

25 Greenfield JR, Farooqi IS, Keogh JM, et al. Oral glutamine increases circulating glucagon-like peptide 1 , glucagon, and insulin concentrations in lean, obese, and type 2 diabetic subjects. Am J Clin Nutr 2009; 89: 106-113.

26 Krog-Mikkelsen I, Hels O, Tetens I, Holst JJ, Andersen JR, Bukhave K. The effects of L-arabinose on intestinal sucrase activity: dose-response studies in vitro and in humans. Am J Clin Nutr 2011; 94: 472-478

27 Moran-Ramos S, Tovar AR, Torres N. Diet: friend or foe of enteroendocrine cells--how it interacts with enteroendocrine cells. Adv Nutr 2012; 3: 8-20.

28 Reimer RA, Darimont C, Gremlich S, Nicolas-Métral V, Rüegg UT, Macé $\mathrm{K}$. A human cellular model for studying the regulation of glucagon-like peptide-1 secretion. Endocrinology 2001; 142: 4522-4528.

29 Kim K-S, Egan JM, Jang HJ. Denatonium induces secretion of glucagon-like peptide-1 through activation of bitter taste receptor pathways. Diabetologia 2014; 57: 2117-2125.

30 Mundell SJ, Matharu AL, Pula G, Roberts PJ, Kelly E. Agonist-induced internalization of the metabotropic glutamate receptor 1a is arrestin- and dynamin-dependent. J Neurochem 2001; 78: 546-551.

31 Kelly E, Bailey CP, Henderson G. Agonist-selective mechanisms of GPCR desensitization. Br J Pharmacol 2008; 153 (Suppl 1): S379-S388.

32 Smeets AJ, Westerterp-Plantenga MS. The acute effects of a lunch containing capsaicin on energy and substrate utilisation, hormones, and satiety. Eur J Nutr 2009; 48: 229-234.

33 Kim MJ, Son HJ, Song SH, Jung M, Kim Y, Rhyu MR. The TRPA1 agonist, methyl syringate suppresses food intake and gastric emptying. PLoS One 2013; 8: e71603

34 Adisakwattana S, Moonsan P, Yibchok-Anun S. Insulin-releasing properties of a series of cinnamic acid derivatives in vitro and in vivo. J Agric Food Chem 2008; 56: 7838-7844.

35 Ong KW, Hsu A, Tan BK. Chlorogenic acid stimulates glucose transport in skeletal muscle via AMPK activation: a contributor to the beneficial effects of coffee on diabetes. PLoS One 2012; 7: e32718.

36 Kim W, Egan JM. The role of incretins in glucose homeostasis and diabetes treatment. Pharmacol Rev 2008; 60: 470-512.

37 Gribble FM, Williams L, Simpson AK, Reimann F. A novel glucosesensing mechanism contributing to glucagon-like peptide-1 secretion from the GLUTag cell line. Diabetes 2003; 52: 1147-1154.

38 Drucker DJ. The role of gut hormones in glucose homeostasis. J Clin Invest 2007; 117: 24-32. 